\title{
"Y dice que adora piedras": Guaman Poma de Ayala y la construcción discursiva de la materialidad de las idolatrías indígenas
}

\author{
"And they say that [they] worship stones": Guaman Poma de Ayala and \\ the discursive construction of Indigenous idolatries
}

\author{
Laura León-Llerena \\ Durham University, Durham, Reino Unido \\ Contacto: laura.m.leonllerena@durham.ac.uk \\ https://orcid.org/0000-0003-0859-2138
}

\begin{abstract}
Resumen
Este ensayo analiza las estrategias narrativas de Guaman Poma de Ayala para abordar las ideas de materialidad en la cultura andina. Este trabajo se concentra en el sistema descriptivo y clasificatorio desplegado en la Nueva corónica y buen gobierno para reconstruir textualmente la dimensión material de la llamada "idolatría". El cronista fue asistente de Cristóbal de Albornoz, autor de uno de los primeros tratados sobre la extirpación de idolatrías. Guaman Poma incorporó en su crónica información de sus viajes con el visitador para dar cuenta de la diversidad de objetos que pasaron a ser clasificados como idolátricos. El cronista andino coincidió con Albornoz en la necesidad de erradicar objetos y prácticas indígenas que pudieran obstaculizar la conversión de los indios al cristianismo. Sin embargo, observamos que en su texto emerge una tensión ausente en el discurso de Albornoz: la tenaz y resistente heterogeneidad de las culturas andinas frente al proceso necesariamente homogeneizador del discurso sobre "idolatrías".
\end{abstract}

Palabras claves: Felipe Guaman Poma de Ayala; Materialidad; Huaca; Idolatría; Heterogeneidad; Conversión.

\begin{abstract}
This essay studies Guaman Poma de Ayala's narrative strategies to address ideas about materiality in Andean culture. It focuses on the descriptive systems and classifications that are displayed along the Nueva corónica y buen gobierno to textually reconstruct the material dimension of what was called "idolatry". The chronicler was Cristóbal de Albornoz's assistant. Albornoz authored one of the first treatises about the extirpation of idolatries. Guaman Poma included in his work information collected during his time with Albornoz about diverse objects that were classified as idolatric. The Andean author agreed with Albornoz on the
\end{abstract}


necessity to eradicate Indigenous objects and the rituals associated with them because these posed obstacles to the conversion of the Indians to Christianity. One can observe, however, that in Guaman Poma's text there is a discursive tension that is absent in Albornoz's writings. This is evidence of the resistant heterogeneity of Andean cultures before the homogeneizing process of discourses about "idolatries".

Keywords: Felipe Guamán Poma de Ayala; Materiality; Huaca; Idolatry; Heterogeneity; Conversion

Recibido: 17.09.19 Aceptado: 19.11.19

Son pocos los documentos coloniales de la región andina que incluyen el punto de vista indígena sobre las campañas de extirpación de idolatrías. Felipe Guaman Poma de Ayala, indio ladino descendiente de la nobleza indígena prehispánica (los yarovilcas allauco huánucos y los incas) y autoproclamado cronista y príncipe, incluyó en su Nueva corónica y buen gobierno (1615) el testimonio de muchos indios que vivieron y sufrieron los efectos más violentos de la evangelización forzada. Uno de los aspectos más notables de ese testimonio es la información que ofrece el cronista, a través de la voz de otros indios, sobre el proceso de reducción simbólica y material de la cultura indígena dentro del marco ideológico de la extirpación de idolatrías. Me refiero a la estrecha relación que el discurso evangelizador cristiano en los Andes estableció entre huaca ${ }^{1}$, ídolo y piedra. A finales del siglo XVI e inicios del XVII, la relación entre esos términos estaba ya tan asentada que los propios indios acusados de idólatras hacen referencia a ella, como se lee en varios pasajes de la Nueva corónica. Por ejemplo, en su viaje a Lima, emprendido por el cronista para entregar personalmente una copia de su extensa carta al rey a las autoridades pertinentes, Guaman Poma halló que los indios Yauyos y Huachos se encontraban alborotados porque los curas de la doctrina de San Cristóbal los habían acusado falsamente de idólatras:

[...] para hazelle mal y daño a los yndios, leuanta testimonio, deziéndole hechisero que adoraua a las piedras. Y para ello comensó a colgalle de uno a uno a los biejos y biejas y a los niños y atormentalle hasta hazelle hablar falsamente. Con el dolor dixeron que tenía uacas ýdolos; mostrauan piedras de deferentes maneras. (p. 1111; el énfasis mío) ${ }^{2}$ 
Más adelante, mientras proseguía con su viaje, el autor indígena encontró a tres indias viejas y pobres que huían de Hatun Jauja. En el diálogo que sostuvieron con el cronista, ellas relataron que habían dejado su pueblo debido a una campaña de extirpación de idolatrías que llevaba a cabo el cura doctrinero y visitador Francisco de Ávila: “A causa del dotor [Ávila] dixeron que le quería hacer hicheseros y hechiseras, el quien dize en la pregunta ques uaca, [divinidad local], mocha [reverenciar]. Cin auello cido, se huelga y dize que adora piedras" (p. 1121; el énfasis mío). Según el relato de estas mujeres, el padre Ávila acusaba falsamente de hechicería e idolatría a los indígenas de la zona y los castigaba atándoles una soga al cuello y quemándoles la mano con una vela o subiéndolos a un carnero blanco para azotarles hasta que la sangre tiñera el pelaje del animal. Esta situación llevó a algunos indios a huir del pueblo y a otros, aún más desesperados, al suicidio (pp. 1120-1121).

Aunque tras este tipo de encuentros Guaman Poma condenaba los abusos de los curas y clamaba por justicia terrena y divina para los indios "pobres de Jesucristo", el cronista no guardaba simpatía por quienes persistían en las creencias y prácticas prehispánicas andinas. Recordemos que los primeros folios de la Nueva corónica están dedicados a afirmar y demostrar su sincera adhesión a la religión cristiana y la de sus antepasados desde la llegada de los españoles a la región andina (pp. 1-21). Hay asimismo una serie de folios dedicados a describir y condenar las prácticas idolátricas indígenas tanto antes como después del primer encuentro con los europeos. Aún más, los diálogos citados no constituían la primera experiencia de Guaman Poma con las campañas de extirpación de idolatrías. Años antes, aproximadamente en 1582, el cronista había hecho su primer viaje a Lima acompañando al visitador Albornoz, quien cobró notoriedad en el virreinato peruano al autoproclamarse descubridor del movimiento mesiánico indígena conocido como Taqui Onqoy (Duviols, 1977, 133-145; Guibovich Pérez, 1991; Millones, 1971). Autor de la Instrucción para descubrir todas las guacas del Pirú y sus camayos y haciendas (ca. 15811585), uno de los primeros tratados o manuales para los futuros extirpadores de idolatrías, Albornoz describió en varios documentos (llamados “informaciones") 
el celo con el que recorría los pueblos y las comunidades de los Andes buscando y destruyendo objetos de idolatría indígena y castigando a quienes continuaban practicando rituales sagrados prehispánicos. El visitador eclesiástico fue particularmente detallado en la información que dio sobre su estancia en la provincia de Huamanga desde 1569 a 1571, donde reprimió con fuerza cualquier evidencia y vestigio del Taqui Onqoy ${ }^{3}$.

Durante su trabajo como intérprete y asistente de Albornoz en la zona de Huamanga, Guaman Poma incluyó información recogida en ese período, principalmente en el "Capítvlo de los ídolos. Vaca Billca Incap", pero también en otro titulado "Del mvndo bvelbe el avtor a sv casa", donde relata el segundo viaje del autor a Lima (Adorno, 1978, pp. 134-136; Duviols 1977, pp. 284-285). Guaman Poma señaló que Albornoz castigaba "cruelmente" a los idólatras y que destruía los objetos indígenas de culto religioso que encontraba. Al mismo tiempo, el indio ladino tenía cuidado de afirmar que el visitador eclesiástico era un buen funcionario de la corona y de la Iglesia católica: "Fue llano santo hombre, temeroso de Dios. Y ancí hizo todo el seruicio de Dios en este rreyno" (p. 690). En toda la Nueva corónica, el cronista andino expresó un punto de vista ortodoxo respecto a la evangelización, aunque incluyó críticas explícitas a los abusos que algunos curas cometían contra los indígenas con la excusa de extirpar idolatrías. Guaman Poma no duda en insistir en la importancia de adoctrinar a todos los pobladores indígenas y en la necesidad de destruir los lugares y los objetos que pudieran sostener el vínculo con el sistema de creencias religiosas del pasado prehispánico ${ }^{4}$.

La aceptación de la extirpación como parte necesaria del proceso de evangelización no hace sorprendente que Guaman Poma dedicara varios folios a nombrar y describir aquellas prácticas y objetos indígenas que debían ser erradicados. Sus descripciones en cierta medida siguen una línea de catalogación similar a la establecida por Albornoz en la Instrucción. Tanto en el texto de Albornoz como en la Nueva corónica se observa la homogeneización de una amplia variedad de elementos materiales de la cultura indígena, lo cual permite establecer una relación clave para los discursos y las prácticas de extirpación. 
Una de estas homogeneizaciones consistía en establecer y repetir la sinonimia entre huacas como piedras e ídolos o demonios. De ahí que la acusación "dice que adora piedras" incluida en el testimonio indígena recogido por el cronista es aparentemente autoexplicativa para quien acusa a otros de idólatras y también para quien escribe o lee sobre idolatrías indígenas a finales del siglo XVI.

Ahora bien, en los testimonios incluidos en la crónica guamanpomiana que he citado líneas arriba hay una crítica implícita muy importante: desde el punto de vista de los indios, los curas doctrineros y los extirpadores de idolatrías no entendían la dimensión material de las culturas andinas y, por ello, eran incapaces de distinguir a una piedra de un huaca. Así, bajo la mirada de un cura, como se puede comprobar en la Instrucción de Albornoz, casi cualquier objeto indígena se convertía en ídolo y, por tanto, el proyecto de evangelización se hacía virtualmente inacabable e imposible (Duviols, 1967, p. 19). Y si bien Guaman Poma utilizaba el vocabulario de los extirpadores, particularmente la sinonimia entre huaca e ídolo, su obra opera en sentido contrario al de la "petrificación" cultural emprendida por clérigos y oficiales españoles. Como mostraré en lo que sigue de este ensayo, el cronista andino crucialmente reintroduce la heterogeneidad material del mundo andino al ofrecer detalladas descripciones de objetos y proponer una diferenciación entre los de carácter religioso frente a los de uso y práctica cotidiana. Asimismo, al reconstruir narrativamente los contextos culturales y sociales específicos de los objetos, Guaman Poma nos ofrece claves importantes para entender cómo se entrelazaba la idea de materialidad con el sentido de lo sagrado y de lo social en el mundo andino de los siglos XVI y XVII.

\section{No todas las piedras son huacas}

Se puede argumentar que la extirpación de idolatrías implicaba destrucción cultural a dos niveles: la material y la contextual. La primera consistía en la búsqueda y destrucción de objetos considerados ídolos. Estos objetos llegaron a cumplir un rol importante en los autos de fe llevados a cabo en Lima. La destrucción contextual, en cambio, ocurría sobre todo a nivel textual. Me refiero a la descripción y catalogación que se hacía en relaciones, crónicas, historias e 
informaciones sobre el efecto idolátrico de los objetos destruidos o prohibidos. En estos textos se les presenta totalmente desconectados de sus contextos culturales y disociados de las prácticas sociales específicas en que se les utilizaba. Se borraban, de esta manera, los rastros de las relaciones entre personas, espacios y objetos que daban sentidos particulares a estas tres instancias.

La destrucción contextual no es evidente a primera vista y la Instrucción de Albornoz es un ejemplo importante de ello. Este texto, antecedente crucial de documentos mucho más conocidos sobre idolatrías andinas como La extirpación de la idolatría en el Perú (1621) del jesuita Pablo José de Arriaga, entre otros ${ }^{5}$, propone un esquema clasificatorio de los objetos que debían ser destruidos, como leemos en el siguiente ejemplo: "Provincia de los Paltas. Acacana, huaca principal de los indios paltas, eran unas piedras en un cerro junto al pueblo de Cuxibamba en el camino real. Era su pacarisca ${ }^{6}$. Tiene esta provincia otras muchas, como las demás provincias" (Duviols, 1967, p. 32; énfasis mío). Tal como en el caso de la Acacana, nombre atribuido a un huaca andino, la Instrucción generalmente consideraba las siguientes categorías para la clasificación de estos espacios/ manifestaciones de lo sagrado andino: la ubicación geográfica, el nombre del huaca, el grupo étnico al que estaba asociado, el tipo de objeto (piedra, cerro) y la jerarquía del huaca. Es decir, presenta información sobre los elementos que podrían ayudar a reconstruir el contexto social y simbólico. Sin embargo, toda esta información no hace posible reconstruir la lógica de la relación entre lo sagrado y lo material ("unas piedras") ni distinguir matices en la jerarquía de lo material ("un cerro") y de lo sagrado para las diferentes comunidades indígenas. De ahí que Albornoz afirmara que la descripción de la Acacana en la provincia de Paltas es aplicable a "las demás provincias".

Pero más interesante aún, la ausencia de una indagación (que evidentemente iba más allá de los intereses prácticos del visitador eclesiástico) sobre el proceso mediante el cual los objetos se convirtieron en elementos sagrados y cómo se establecieron jerarquías de sacralidad entre ellos nos lleva a comprender que casi todos los objetos relacionados con las sociedades indígenas podían ser agrupados bajo la categoría general de ídolos o huacas. Entre algunos 
de los objetos de idolatría que Albornoz menciona en la Instrucción se incluyen las piedras pequeñas, las piedras grandes, los objetos (naturales o artefactos) que pertenecieron a los incas (desde uñas y cabellos hasta vestimentas y armas), las figuras talladas en piedra, los primeros frutos de una cosecha, las piedras bezoares a las que se atribuían propiedades medicinales y se podían encontrar en los estómagos de las llamas, los objetos tocados por rayos y torbellinos, el lugar donde caía un rayo, los cuerpos momificados de los antepasados, los niños que nacían con deformaciones, los gemelos, los montículos de tierra o las piedras que se encontraban en los caminos incas (apachita), las montañas, los lugares como cuevas o lagunas identificadas con el origen mítico de algún ayllu (pacariscas, pacarinas), los vestidos y tocados de plumas o las pieles de animales usados en los bailes o taquíes, las frutas y yerbas medicinales y las serpientes o culebras (amaru). Ante tal amplia diversidad de objetos de idolatría no resulta extraño que la sinonimia entre huaca e ídolo, huaca y piedra, se asentase y extendiese más allá de los textos de los extirpadores. Pero esto no era una simple consecuencia de la necesidad de economizar con el lenguaje. De ser así, el visitador podría haberse ahorrado varios folios que contienen listas de los objetos o "ídolos" destruidos.

Albornoz no fue el único que intentó describir y definir el lado material de lo sagrado en el mundo andino. Si bien se puede decir que entre los estudiosos de las culturas andinas hay un cierto consenso sobre lo que se entiende por la palabra huaca, es importante recordar que hubo una interesante transformación histórica de la definición de ese término, cuyo campo semántico prehispánico no ha podido ser recuperado completamente. Desde los primeros vocabularios coloniales de la lengua quechua producidos por miembros de la Iglesia como Domingo de Santo Tomás en 1563, Diego González Holguín en 1608 y Diego de Torres Rubio en 1619, pasando por memorias y crónicas escritas por administradores españoles como el doctor Murillo de la Cerda en 1589 y Fernando Montesinos en 1642, hasta las nueve definiciones propuestas por el Inca Garcilaso de la Vega en sus Comentarios reales (1609), queda claro que no hubo ninguna dificultad en establecer que huaca aludía a una entidad o expresión de lo sagrado y que merecía ser adorado (Bray, 2015, pp. 5-7; Mills, 1997, pp. 41-42). Creo que la 
complicación para entender el término y el concepto (o los conceptos) que abarca, y en lo que cada uno de los textos citados difiere, se encuentra en la definición de la dimensión material de esa entidad sagrada.

Al igual que Albornoz, los autores mencionados arriba enumeraron una sorprendente y muchas veces disímil variedad de objetos que podían ser considerados huacas. Y sin embargo, esta heterogeneidad para entender y designar lo sagrado comprendido en el término no impidió la transformación discursiva de todos esos objetos en simples piedras. La siguiente cita de la Nueva corónica expone hasta qué punto los curas y extirpadores de idolatría hablaban de "piedras" para referirse a una variedad de objetos. En este episodio que recoge Guaman Poma, un grupo de indios yauyos detalló al autor andino que el cura de la doctrina que los acusó de idólatras por "adorar piedras", después de someterlos a castigos físicos brutales, les arrebató con la ayuda del curaca objetos que no tenían ninguna característica lítica:

Con el principal don Pedro, el dicho padre les quitó todas las galanterías y baxillas de plata y topos [prendedor] y rropa con que ellos en las fiestas cantan y dansan y baylan, como aquilla [vasija de plata] y topos y bestidos, todo de plata, y rropa de cunbe [tejido fino] y de auasca [corriente], uacra [cuerno], pluma chacpac de lana colorado. De todas las casas ajuntó, y de ellas hizo baxillas, y de la llana, sobrecama. (p. 1111)

Hasta aquí he apuntado el proceso por el que cualquier objeto vinculado a la vida cotidiana y a los rituales sagrados indígenas podía ser considerado un huaca y cómo esa variedad de objetos pasaba a reducirse a la palabra "piedra" en los escritos coloniales que hacían referencia a la extirpaciones de idolatrías. Es preciso aclarar que aunque no todas las piedras eran huacas ni todos los huacas eran piedras, la petrificación — la transformación en piedra - era un proceso muy importante en la concepción de lo sagrado en el mundo andino. El rol central que tenían los elementos y artefactos líticos en las cosmogonías y la organización material y social de las culturas andinas prehispánicas es innegable ${ }^{7}$. Sin embargo, quiero enfatizar que la materialización de lo sagrado en la forma de una piedra es muy distinta a la reducción de una diversidad de objetos a la palabra "piedra" 
en español que se hacía en el discurso colonial. A continuación voy a explicar en qué consistía el proceso de petrificación y por qué la destrucción contextual y discursiva llevada a cabo en los documentos de los curas extirpadores de idolatría impide reconstruir la relación clave entre el concepto de lo sagrado y su dimensión material en el lugar y la época que nos ocupa. Para ello empezaré analizando pasajes de la Nueva corónica en los que puede observarse cómo Guaman Poma coincidía en algunos aspectos con la catalogación que hizo Albornoz de los objetos considerados ídolos. También discuto de qué maneras el cronista andino excedió el discurso del visitador y extirpador de idolatrías, dejando entrever la lógica que existía en la relación de lo sagrado con lo material y dando algunas pistas sobre cómo algunos huacas podían transformarse en piedras.

\section{Diálogo con piedras}

La práctica de rituales de adoración de huacas o ídolos y la creación de objetos que podían servir de ofrendas o convertirse en objetos sagrados en sí mismos solo empezó, según Guaman Poma, a partir del periodo incaico de la historia andina. Siguiendo una estrategia repetitiva de descripción similar a la empleada por Albornoz en la Instrucción, el cronista andino detalla que los incas ordenaron la adoración del sol, la luna, las estrellas, el rayo, las piedras, las peñas, las lagunas y otras cosas que no especifica. También añade que entre los objetos que se entregaban como sacrificio a los huacas había comida, coca y chicha, así como tejidos corrientes (auasca) y finos (cumbi), vajilla de oro, plata, barro y mullu [concha], así como cobre (p. 267). Si se consulta la cita que inserté en páginas anteriores sobre el encuentro de Guaman Poma y los indios yauyos, se puede comprobar que algunos de los objetos que fueron arrebatados a los indios acusados de "adorar piedras" aparecen en esta lista de objetos utilizados como ofrendas para un huaca.

Guaman Poma admite que la información sobre ídolos y hechiceros que incluye en su obra, la recogió durante el período en el que trabajó con Cristóbal de Albornoz. Y sin embargo hay una serie de instancias en las que el cronista no solo excede la cantidad de detalles ofrecidos por el visitador en su Instrucción, 
sino que también incluye explicaciones que están ausentes en dichos textos. Un ejemplo claro se encuentra en la comparación de la discusión, en ambos textos, sobre la apachita o camachico que parecen usarse como evidencia de lo sagrado andino. Albornoz los identifica como un huaca muy preocupante por su omnipresencia:

Hay otro género de huacas muy ordinario en todos los caminos y puertos dellos en todo el Perú, que llaman apachita o camachico por otro nombre. Estas las hay en todas las asomadas y vertientes de los caminos, a las cuales saludan y ofrecen los que van con cargas o fatigados de andar, y les ofrecen una oración o una piedra... otros escarban la tierra en la propia huaca [...] otros ofrecen ramos de leña [...]. Son tantos éstos que, si no es con amonestaciones buenas, no se apartarán de la creencia porque encuentran por momentos con ellas en todos los caminos y puertos de toda la tierra. (Albornoz citado por Duviols, 1967, p. 19; énfasis es mío)

Por su parte, al referirse a la apachita, Guaman Poma explica en su crónica que fue Topa Ynga Yupanqui quien ordenó a "los indios de tierra caliente" o a aquellos de la sierra que iban a la tierra caliente que adorasen a Pachacamac en las apachitas, identificadas como lugares de adoración que el viajero podía encontrar en el camino. Dicho ritual se podía efectuar amontonando piedras, dejando flores o paja torcida hacia la izquierda (p. 265). Es decir, el cronista andino aclara que la apachita no es un huaca en sí, sino un lugar donde el inca Topa Yupanqui había ordenado que los viajeros hiciesen ofrendas. Los objetos que los indios dejaban allí, por otra parte, cobraban una dimensión sagrada solo en relación con una deidad o huaca específica identificada con Pachacamac.

Al enfatizar la responsabilidad de los incas en la organización, establecimiento y control de un sistema religioso o "idolátrico" en todos los territorios que controlaban, Guaman Poma revela que incluso había autoridades indígenas encargadas de constatar el correcto desarrollo de los rituales sagrados. Así, en el capítulo sobre los ídolos y huacas de los Collasuyos, el autor explica que los indios de un determinado lugar hacían los sacrificios en honor al espíritu 
del cerro ante la presencia de gobernadores reales de los incas equivalentes a veedores o visitadores y jueces quienes, a su vez, enviaban reportes al inca en Cuzco detallando cómo se desarrollaban anualmente los sacrificios:

Los Poma Canches sacrificauan al serro de Canchi Circa con oro y plata y otras mundicias, quemándolos y enterrándolo con un niño y niña de doze años. Los sacrificauan acimismo en otras uacas ýdolos que ay muchas que por prolixidad no lo escribo. Lo mochauan [adoraban] y sacrificauan cada pueblo y cada prouincia en cada año, como estaua ordenado por los Yngas a sacrificar a los ýdolos y uacas.

Y de todo ello les dauan cuenta y rrelación al dicho Ynga y lo hacían estos dichos sacrificios en presencia de los corregidores tocricoc y de los jueses michoc yngas. Éstos enbiaua por la posta y chasque [postillón] a la cauesa deste rreyno abisar de lo que pasa del sacrificio. (p. 273)

Aunque Guaman Poma insiste en que eran los incas quienes impusieron la idolatría en todo el Tahuantinsuyo y ordenaban que ciertos tipos de adoraciones y sacrificios se debían hacer a los huacas, la información que presenta — como evidencia la cita anterior - sugiere que las dinámicas sociales y los contextos geográficos de cada etnia también informaban las relaciones entre sujetos, objetos y la esfera de lo sagrado. De ahí que para el cronista andino fuera importante establecer una diferenciación entre las regiones del imperio (suyos) a las que pertenecían los idólatras: los Chinchaysuyos (noreste y centro), los Andesuyos (Amazonía) y los Collasuyos (sur y suroeste), aunque no menciona a los Contisuyos (oeste central) en el capítulo de los ídolos (pp. 263-288). El autor es más específico cuando detalla las diferencias en rituales y objetos idolatrados o sacrificados según las etnias. Así, por ejemplo, al hablar de los Chinchaysuyos, presenta a los indios yauyos como adoradores del huaca Pariacaca y explica que en su honor se hacían ofrendas de chicha, mullu (un tipo de concha marina), uaccri zanco (pan remojado en sangre), conejos y comidas. En contraposición a esto, Guaman Poma señala que los indios huancas de la sierra central adoraban al huaca Carhuancho Uallallo en cuyo honor sacrificaban perros, coca, comidas y conchas de moluscos marinos (p. 269). Ambos grupos étnicos utilizaban el mullu como objeto para rendir culto a un huaca. 
Cabe preguntarse aquí por qué un indio ladino, que insistía en su sincero y ortodoxo catolicismo, se dio la molestia de expandir el trabajo descriptivo del visitador para el cual prestó servicios extirpando idolatrías. Se puede argumentar que al especificar en sus descripciones que cada grupo honraba a una deidad distinta, Huamán Poma sugería que el concepto de lo sagrado, o más bien la construcción simbólica de cada entidad sagrada (Pariacaca y Carhuancho Uallallo en este ejemplo), estaba intrínsecamente relacionada con los objetos que se dedicaban a su culto y que, por tanto, la dimensión material y simbólica de dichos objetos también dependía y se transformaba según la relación particular con cada entidad sagrada. Es decir, que así como no toda piedra era un huaca, ni todos los huacas eran iguales, tampoco el aparentemente mismo objeto, el mullu en este caso, significaba lo mismo para los adoradores de Pariacaca y los de Carhuancho Uallallo. Pero entonces ¿qué simbolizaba el mullu para cada grupo étnico en los contextos que describe el cronista? Guaman Poma omite narrar los orígenes míticos y acciones sobrenaturales de los dioses fundadores de los diferentes ayllus que habitaban en el Tahuantinsuyo, borrando así el contexto (mítico) que nos permitiría reconstruir en detalle la relación clave entre el concepto de lo sagrado y su dimensión material.

Existe, afortunadamente, un texto contemporáneo a la Nueva corónica que reúne una serie de narraciones sobre los dioses tutelares de los diversos grupos étnicos que habitaban la región de Huarochirí y cuyos relatos fueron recogidos justamente como parte de una campaña de extirpación de idolatrías. En el documento escrito en quechua pastoral conocido como el Manuscrito de Huarochirí (ca. 1598-1608), el narrador anónimo incluye detallados relatos sobre los dioses Pariacaca, Huallalo Caruincho, Pachacamac, entre otros, así como la relación de estos huacas con espacios geográficos específicos y con los hombres. En esas historias se explica, por ejemplo, que Huallalo Caruincho (que en el texto de Guaman Poma aparece como Carhuancho Uallallo) creó aves de varios tipos que poseían plumas de deslumbrantes colores amarillo y rojo. Pero tras ser derrotado por Pariacaca, Huallalo fue expulsado junto a sus creaciones a la región de los Antisuyos (en Taylor, 2008, p. 23). Dado que las plumas 
amarillas y rojas son parte del relato mítico de la derrota de Huallallo, no sería sorprendente que esas plumas pudieran tener significaciones muy diferentes para los adoradores de uno y de otro huaca. Más allá de esta hipótesis, en el Manuscrito de Huarochirí hay relatos en los que explícitamente se observa cómo algunos huacas ordenan el tipo de objetos que se deben emplear como ofrendas sagradas. Pero, más importante aún para el propósito de este ensayo, ese texto explica el proceso por el cual un dios o huaca podía transformarse en piedra.

En la antigüedad mítica narrada por el manuscrito, los seres humanos convivían y a veces desafiaban, competían y seducían a los dioses. Cuando estos personajes habían completado alguna hazaña o habían sido derrotados por un huaca más poderoso, se transformaban en otra entidad, por voluntad propia o por imposición del vencedor: en piedras. En el caso de seres humanos, al ser petrificados se transformaban en entidades sagradas o huacas. Pero los que ya eran dioses antes de la petrificación mantenían su estatus divino bajo la forma de piedras. La transformación en piedra (o cerro o montaña) aseguraba que el personaje en cuestión dejase en el paisaje una huella concreta de su paso por el territorio de sus descendientes humanos. También garantizaba el recuerdo de las hazañas (o derrotas) del huaca y exigía una permanente atención de sus descendientes humanos que formaban parte de ayllus y proveerían ofrendas rituales. Cada huaca petrificado tenía una historia y un ritual particular (Bray, 2015; Dean, 2010; Mills, 1997, pp. 46-51; Rubina, 1992; Salomon \& Urioste, 1991, pp. 18-19; Taylor, 2008).

Es importante notar que aunque Guaman Poma omite incluir las historias particulares de los huacas y explicarnos cómo lo sagrado se relacionaba con lo material, y viceversa, queda claro, así, que para él no todas las piedras eran iguales. Si bien en la Nueva corónica el cronista establece en varias ocasiones la relación de sinonimia entre huacas, piedras y demonios, lo que es notable es que esas "piedras" son visualmente - es decir, en sus dibujos - objetos con identidades 
particulares y distintas. Al inicio del capítulo de los ídolos, en el folio 263, se presenta la imagen de Tupa Inga Yupanqui dialogando con doce o trece figuras de huacas y willcas (una entidad sagrada asociada con ancestros):

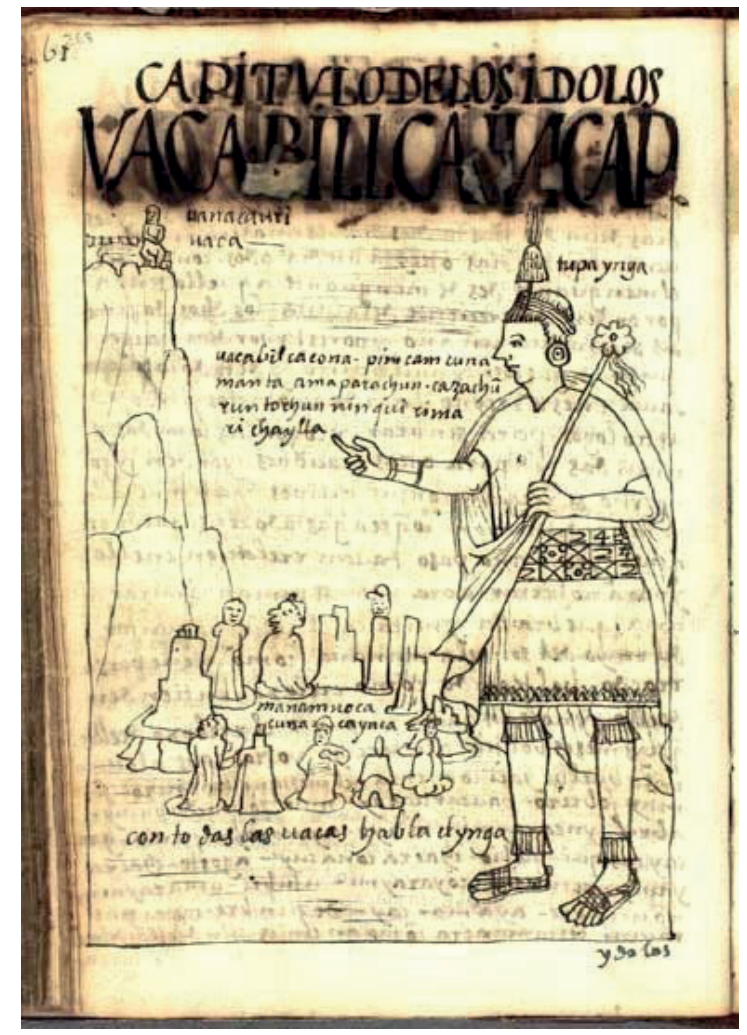

Figura 1. Nueva corónica y buen gobierno (1615), p. 263. Biblioteca Real de Copenhague, Dinamarca.

Guaman Poma escribió el nombre de cada uno de esos huacas dentro de la ilustración, con lo que sugirió diferencias entre las deidades. Pero lo que realmente nos revela una identidad particular es la forma con la que el cronista dibuja a cada uno de los dioses y sus personificaciones: algunas de esas figuras son antropomorfas, mientras que otras parecen pequeñas representaciones de 
diferentes cerros o montañas. En la Nueva corónica, como ya han notado varios investigadores, hay dos niveles discursivos complementarios: el textual y el visual (Adorno, 2000 [1986]; Cummins, 1992; López-Baralt, 1988; QuispeAgnoli, 2006, pp. 193-205). En el caso de la materialidad de los ídolos, las ilustraciones de Guaman Poma consiguen expresar una heterogeneidad que la lengua escrita, herramienta fundamental en el proceso de evangelización y extirpación de idolatrías, parece no permitir más. El cronista no nos ofrece ningún relato que pueda explicar las particularidades de cada uno de esos huacas ni tampoco cómo y por qué cobraron una dimensión material específica.

Entonces, ¿cómo podemos comprobar que para Guaman Poma la dimensión material de lo sagrado era importante? Para responder a esa pregunta y concluir este ensayo regreso a uno de los capítulos iniciales de la Nueva corónica y buen gobierno. En el capítulo de las edades de los indios (pp. 48-78), Guaman Poma establece una genealogía que tiene como punto de partida un extenso período anterior a la aparición de los incas. Esa genealogía también es la historia del desarrollo de las idolatrías en el Perú, que el cronista atribuye a los incas. Pero más allá de la evidente intención de enaltecer las virtudes de los indios preincaicos y subrayar la responsabilidad de los incas por la introducción de ídolos y rituales idolátricos, hay también en esa sección una muy interesante reflexión sobre la relación entre un estado cultural primitivo y la incapacidad de concebir una dimensión material del mundo sagrado.

Los primeros indios, los Wari Wira Cocha Runa, eran descendientes directos de Noé y su generación duró “ochocientos y treinta años” (pp. 48-49): 




Figura 2. Nueva corónica y buen gobierno (1615), p. 48.

Biblioteca Real de Copenhague, Dinamarca.

Su estado primitivo queda establecido en frases como: "Y esta gente no sauía hazer nada, ni sauía hazer ropa... Ni sauía hazer casas" (pp. 49-50) y "Esta gente no supieron de dónde salieron ni cómo ni de qué manera, y ancí no ydulatrauan a las uacas ni al sol, ni a la luna, estrellas ni a los demonios..." (pp. 50-51). Guaman Poma añade que esta primera generación de indios (y todas las que siguieron antes de los incas), al descender directamente de Noé, sí tenia conocimiento del verdadero $\operatorname{Dios}^{8}$, lo que sin embargo no impedía una sensación de abandono: "Hincado de rrodilla, puesta las manos y la cara, mirando al cielo, pedían salud y merced y clamauan con una bos grande, deziendo: 'Maypim canqui, maypim canqui, yaya' [¿Dónde estás, dónde estás, padre mío?]” (pp. 50-51). Puede argumentarse que en esta sección Guaman Poma recalca el 
estado primitivo de esa primera generación de indios, con lo que insiste en su incapacidad inicial de producir cultura material (como ropa y casas, pero también ídolos). Aunque los Wari Wira Cocha Runa tenían una noción del Dios verdadero que luego olvidaron y sustituyeron por dioses andinos, el reclamo de la ausencia de Dios tiene que ver con lo material y no con lo espiritual. Es decir que, al clamar “¿Dónde estás, padre mío?”, no solo se expresa la incertidumbre sobre la existencia del verdadero dios, sino que también se pone en evidencia cómo la ausencia de una expresión material de lo divino era considerada por el cronista como un signo de primitivismo.

En conclusión, acusar a los indios de idólatras por "adorar piedras" parece haber sido una práctica común entre los curas de doctrinas a finales del siglo XVI e inicios del XVII. Así lo sugieren los testimonios de algunos indios con los que Guaman Poma se encontró en diferentes partes de su segundo viaje a Lima. Sin embargo, como espero haber demostrado en este ensayo, la relación entre piedras e idolatría merece ser analizada con relación a las descripciones y explicaciones que el cronista andino ofrece sobre los rituales y las prácticas idolátricas en el mundo andino.

En mi opinión, con esa información Guaman Poma reintroduce la heterogeneidad de la cultura material andina reducida a "piedras" en los discursos de los curas doctrineros y extirpadores de idolatrías. Se trata de una heterogeneidad de objetos, pero también de una diversidad de interacciones entre el espacio de lo sagrado y el mundo material. Como he argumentado, estas interacciones nos sugieren que los objetos podían cobrar significados particulares dependiendo del contexto social y simbólico. De ese modo, aunque Guaman Poma presenta en varias ocasiones a la palabra huaca como sinónimo de piedra y esta como materialización de un ídolo (o un demonio), también incluye suficiente información para hacernos entender que una piedra no siempre era un huaca y que un huaca no siempre era una piedra.

\section{Notas}

1 Este vocablo quechua hace referencia a alguna entidad sobrenatural y sagrada que podía cobrar la forma de un objeto (como una piedra o el cuerpo momificado de un antepasado), un elemento de la geografía (un cerro, una laguna), un lugar (una cueva), etc. 
2 Todas las citas textuales provienen de la edición digital, con paginación corregida, que se puede consultar aquí: http://www.kb.dk/permalink/2006/poma/info/en/frontpage. htm (Guaman Poma, 2001 [1615]). Esta numeración también se encuentra en la edición de la crónica de 1980.

3 Este movimiento mesiánico indígena proclamaba la derrota del dios cristiano, el final de la presencia española en los Andes y el resurgimiento de las divinidades andinas o huacas.

4 Se puede observar en la Nueva corónica un cambio paulatino de actitud de Guaman Poma respecto a los métodos de evangelización y adoctrinamiento de los indígenas (Adorno, 1978, pp. 131-136).

5 Otro ejemplo significativo es Exhortaciones e instrucciones acerca de los indios del Arzobispado de Lima (1649) de Pedro de Villagómez. Duviols discute la influencia de los escritos de Albornoz en otros extirpadores de idolatrías como Arriaga y Villagómez (2003, p. 28).

6 Pacarisca es el lugar de origen mítico de un ayllu.

7 En tal sentido estoy de acuerdo con Van de Guchte y Rubina en que se puede hablar de un "discurso lítico andino" (Rubina, 1992, p. 71). Como ejemplo de la importancia de la piedra para la construcción simbólica y material de las culturas andinas, véase el libro más reciente de Carolyn J. Dean (2010).

8 Cfr. Adorno (1978, 127-128) para una discusión sobre los debates entre los cronistas contemporáneos a Guaman Poma respecto al origen de los indios del Nuevo Mundo.

\section{Referencias bibliográficas}

Adorno, R. (1978). Felipe Guaman Poma de Ayala: An Andean View of the Peruvian Viceroyalty, 1565-1615. Journal de la Société des Americanistes, 65, 121-143. Recuperado de https://www.persee.fr/doc/ jsa_0037-9174_1978_num_65_1_2159

Adorno, R. (2000 [1986]). Guaman Poma: Writing and Resistance in Colonial Peru. Austin: University of Texas Press.

Bray, T. L. (2015). The Archaeology of Wak'as: Explorations of the Sacred in the Pre-Columbian Andes. Boulder: University of Colorado Press.

Cummins, T. B. F. (1992). The Uncomfortable Image: Pictures and Words in the Nueva Corónica y Buen Gobierno. En R. Adorno (Ed.), Guaman Poma 
de Ayala: The Colonial Art of an Andean Author (pp. 46-59). Nueva York: The Americas Society.

Dean, C. (2010). A Culture of Stone: Inka Perspectives on Rock. Durham: Duke University Press.

Duviols, P. (1967). Un inédit de Cristóbal de Albornoz: La Instrucción para descubrir todas las guacas del Pirú y sus camayos y haciendas. Journal de la Société des Américanistes, 56(1), 7-49. Recuperado de https:// www.persee.fr/doc/jsa_0037-9174_1967_num_56_1_2269

Duviols, P. (1977). La destrucción de las religiones andinas: conquista y colonia. Ciudad de México: Universidad Nacional Autónoma de México.

Duviols, P. (Ed.). (2003). Procesos y visitas de idolatrías: Cajatambo, siglo XVII con documentos anexos. Revisión paleográfica: Laura Gutierrez Arbolú y Luis Andrade Ciudad; selección de textos y estudios históricos: Pierre Duviols; textos quechuas traducidos, editados y anotados por César Itier. Lima: Instituto Francés de Estudios Andinos, Pontificia Universidad Católica del Perú.

Guaman Poma de Ayala, F. (1980 [1615]). Nueva corónica y buen gobierno. Edición de R. Adorno, J. Murra y G. Urioste. Madrid: Siglo XXI.

Guaman Poma de Ayala, F. (2001 [1615]). El sitio de Guaman Poma. Nueva corónica y buen gobierno. Copenhague: Biblioteca Real. Recuperado de http://www.kb.dk/permalink/2006/poma/info/en/frontpage.htm

Guibovich Pérez, P. M. (1991). Cristóbal de Albornoz y el Taki Onqoy. Histórica, 15(2), 205-236. Recuperado de http://revistas.pucp.edu.pe/index.php/ historica/article/view/7868

López-Baralt, M. (1988). Icono y conquista. Madrid: Hiperión.

Millones, L. (1971). Las Informaciones de Cristóbal de Albornoz: documentos 
para el estudio del Taki Onkoy. Cuernavaca: Centro Incultural de Documentación.

Mills, K. (1997). Idolatry and Its Enemies: Colonial Andean Religion and Extirpation, 1640-1750. Princeton: Princeton University Press.

Quispe-Agnoli, R. (2006). La fe andina en la escritura: Resistencia e identidad en la obra de Guamán Poma de Ayala. Lima: Fondo Editorial de la Universidad Nacional Mayor de San Marcos.

Rubina, C. (1992). La petrificación en el Manuscrito de Huarochirí. Mester, 21(2), 71-82. Recuperado de https://escholarship.org/uc/item/50s6z2z7

Salomon, F. \& Urioste, G. (1991). The Huarochiri Manuscript: A Testament of Ancient and Colonial Andean Religion. Austin: University of Texas Press.

Taylor, G. (2008). Ritos y tradiciones de Huarochirí. Lima: Instituto Francés de Estudios Andinos, Instituto de Estudios Peruanos, Universidad Nacional Mayor de San Marcos. 